Velásquez García, Mario Alberto (2009), Las luchas verdes. Los movimientos de Tepoztlán (Morelos)

y Cytrar en Hermosillo (Sonora), México, El Colegio de Sonora, 543 p.*

\title{
Francisco Zapata**
}

En los últimos treinta años (1980-2010) la historia de México ha sido atravesada por la transformación radical del modelo de desarrollo de la industrialización por sustitución de importaciones y por el intento, todavía inconcluso, de instalar un proceso de transnacionalización del mercado interno que incluye una transformación del régimen político, la que culminó en la alternancia del año 2000 con la llegada del Partido Acción Nacional al poder presidencial. ${ }^{1}$

Estas transformaciones, estrechamente ligadas, han sometido a los mexicanos a fuertes tensiones, entre las cuales destacan el resurgimiento del movimiento urbano popular después del terremoto de 1985, la irrupción del movimiento zapatista en enero de 1994, así como varios conflictos laborales que se derivan de la sobrevivencia del corporativismo como sistema de articulación entre el Estado y la sociedad civil.

Las tensiones mencionadas han afectado a un amplio espectro de la sociedad mexicana. Las clases medias, los indígenas, los intelectuales y los artistas, los campesinos, los jóvenes, los sindicatos y otros actores sociales como los obreros y las mujeres viven estos procesos sin que hasta ahora sea evidente que puedan beneficiarlos, y por ello en muchas ocasiones han manifestado su inconformidad por la forma en que se les han impuesto. La inconformidad se ha manifestado de maneras novedosas sin que sea posible asimilarlas a las que adoptaron en el periodo histórico anterior (1935-1980). Manifiestan la presencia de profundos agravios derivados del estancamiento económico, del dete-

* Este libro se basa en la tesis doctoral de Mario Alberto Velásquez García, "Nosotros queremos a la ecología. Organizaciones ecológicas y movimientos ambientales, sus recursos y sus formas: el caso del club de golf en Tepoztlán, Morelos y el Cytrar en Hermosillo, Sonora", El Colegio de México, Programa de Doctorado en Ciencia Social con especialidad en Sociología, 2006, bajo la dirección de la doctora María Luisa Tarrés.

** Profesor investigador de El Colegio de México. Correo electrónico: zapata@ colmex.mx.

${ }^{1}$ Veáse Diana Margarita Favela, Protesta y reforma en México. Interacción entre Estado y sociedad 1946-1997, México, Centro de Investigaciones Interdisciplinarias en Ciencias y Humanidades, UNAM / Plaza y Valdés, 2006.

$\overline{\text { ESTUDIOS DEMOGRÁFICOS Y URBANOS, VOL. 26, NÚM. } 1 \text { (76), 2011, 215-220 }}$ 
rioro de la distribución del ingreso, de la generalización de la violencia institucionalizada, y de procesos que apuntan hacia la desintegración de las relaciones sociales que se habían construido laboriosamente en el periodo anterior.

Los antecedentes mencionados permiten diferenciar las formas clásicas de lo que fuera la lógica de la acción colectiva en México de las que pueden ser formas inéditas, como las que se han manifestado en los últimos treinta años. La aparición de estas formas inéditas de movilización social plantea desafíos analíticos que obligan a salir de las concepciones tradicionales de interpretación de los movimientos sociales. Éste es el desafío que enfrentó Mario Velásquez en su libro Las luchas verdes, cuyo valor reside precisamente en la búsqueda de una interpretación de movimientos que no están inscritos en las perspectivas clásicas.

A partir de la presentación de una atinada síntesis teórica de la perspectiva analítica de la escuela de la movilización de recursos que proporciona las herramientas analíticas para trascender las perspectivas clásicas, Mario Velásquez reconstruye la trayectoria de dos importantes acciones colectivas de los años noventa: la que animaron los ecologistas de Hermosillo (Sonora) en contra de la instalación de residuos tóxicos en las cercanías de la ciudad y la que organizaron los campesinos de Tepoztlán (Morelos) para bloquear la construcción de un club de golf en su localidad. En ambas estuvo en juego la defensa de los recursos naturales, cuestión que no pudo haber servido como detonante en el modelo de desarrollo de la sociedad de producción que imperó en México hasta fines de la década de los ochenta. Esa reconstrucción se realiza frente al telón de fondo de los sexenios de Salinas de Gortari (1988-1994) y de Zedillo (1994-2000), durante los cuales tuvieron lugar las dos acciones colectivas que sirven de sustento a la interpretación de Mario Velásquez.

Cabe aquí insertar el análisis de Las luchas verdes en un marco de referencia interpretativo más general. En efecto, este libro es un aporte importante a lo que Alberto Melucci² denominara la transición entre los movimientos sociales del modelo de desarrollo de la sociedad de producción al modelo de desarrollo de la sociedad de la información. El estudio de lo sucedido en Hermosillo y en Tepoztlán en la década de los noventa nos permite comprenderlas en el marco de esa transición

En esta transición los elementos constitutivos del análisis de la acción colectiva, la identidad, la oposición y la totalidad, que en la so-

${ }^{2}$ Veáse Alberto Melucci, Challenging Codes. Collective Action in the Information Age, Nueva York, Cambridge University Press, 1996. 
ciedad de producción operaron en forma articulada, en el modelo de desarrollo de la sociedad de información lo hacen en forma desarticulada. ${ }^{3}$ Cada uno de ellos tiende a desarrollar una lógica particular de operación. Los efectos de esa desarticulación afectan fuertemente los lugares en los cuales surgirán acciones colectivas, así como el sentido que adoptarán, lo cual precisamente ocurrió en los dos casos estudiados en Las luchas verdes.

El análisis de la nueva articulación entre los elementos constitutivos de los movimientos sociales debe entonces trascender el discurso en términos de movimiento-personaje, típico del escenario de la sociedad de producción. Como ese escenario ha sido sustituido por el de la sociedad de información, es indispensable modificar radicalmente la aproximación analítica a las acciones colectivas que se desarrollan en este marco.

Tanto en Hermosillo como en Tepoztlán los actores experimentaron con recursos que no habían sido centrales en los movimientos sociales de la sociedad de producción, como el uso de la legislación, la búsqueda de vínculos con los medios de comunicación, el desarrollo de prolongados litigios que generaron espacios de negociación inéditos y el uso del conocimiento científico como arma de lucha. Ello dio lugar a la incorporación a los movimientos de actores como los abogados o los "expertos", que en el modelo de desarrollo anterior no eran parte constitutiva de la estructuración de las acciones colectivas. La introducción sistemática de los aspectos institucionales responde a la necesidad imperiosa de estos dos movimientos de enfrentar la "muralla de papel" con que el Estado busca arrinconarlos. La introducción del conocimiento científico-experto en el enfrentamiento con el Estado inaugura una disputa acerca del sentido de la acción estatal que no toma en cuenta los intereses de las personas. El uso de estos recursos les permitió superar las profundas dificultades que tuvieron inicialmente para articular campos de conflicto, para establecer relaciones de tensión con los adversarios y sobre todo para estructurar el principio de totalidad, es decir un proyecto alternativo para eliminar el agravio que los grupos dominantes habían provocado.

Por eso, la desarticulación de los principios de la acción colectiva convierte a los dos casos descritos por Mario Velásquez en movimientos de resistencia, defensivos, sin la posibilidad de establecer una temporalidad y una acumulación de fuerza que fuera más allá de impedir

${ }^{3}$ Veáse Alain Touraine, Sociologie de l'action, París, Editions du Seuil, 1964. 
que se concretaran las iniciativas expoliadoras del medio ambiente, al que buscan defender. Si bien en sus contextos particulares cada acción colectiva tuvo un éxito relativo al bloquear la concreción de esas iniciativas, el balance reitera, una vez más, lo que alguna vez John Womack, ${ }^{4}$ en su biografía de Emiliano Zapata, describiera en forma tan gráfica: "éste es un libro acerca de un pueblo que no quería cambiar y por eso hizo una revolución”.

Existen otras dimensiones del análisis de Las luchas verdes que vale la pena destacar. Una de ellas tiene que ver con la fragmentación de los roles de los actores, con la ausencia de un principio articulador de las identidades, como había sido, por ejemplo, la calificación del trabajo en el movimiento obrero o la relación con la tierra en el caso de los movimientos campesinos. En estos movimientos no existen "obreros" o "campesinos", sino que aparecen más bien "ciudadanos" en Hermosillo, o "pobladores" en el caso de Tepoztlán. El lugar desde el cual se expresa la acción colectiva indica que los actores sociales se definen más como "sujetos" que como agentes de una profesión, de una calificación o de un rol en un sistema de producción. Además, la acción no se reclama de un liderazgo central que pudiera ser el punto de referencia para los actores que la integran, sino que manifiesta un alto grado de especificidad que no permite hablar del movimiento "ecologista" de la misma forma que antes se podía hablar del "movimiento obrero". Por otro lado, las redes entre las cuales circulan los líderes y los movimientos no permiten ubicar claramente las razones por las cuales se desencadenan o desaparecen del escenario, ni tampoco permiten conocer si buscan objetivos que transciendan la inmediatez del cierre del depósito de residuos tóxicos o el bloqueo al campo de golf.

Todo lo anterior implica que a partir del estudio sistemático, detallado, riguroso de estos casos es posible caracterizar la forma que toma la acción colectiva en el México de la transición entre modelos de desarrollo. Enfrentarse al carácter tecnocrático del proceso de toma de decisiones que asume la acción estatal, a la "muralla de papel" que las autoridades construyen para demorar, diferir y bloquear las demandas de los movimientos, confrontar el diagnóstico científico que realizan los "expertos" estatales con el que realizan los "expertos" al servicio del movimiento, son las dimensiones esenciales de las acciones que emprenden. 1970.

${ }^{4}$ Veáse John Womack, Zapata and the Mexican Revolution, Nueva York, Vintage Books, 
En este sentido, y ello aparece con claridad en Las luchas verdes, la clase política, que anteriormente era responsable ante los electores que la elegían, ya no sirve de correa de transmisión hacia las esferas del poder, lo cual queda perfectamente claro, pues en los dos casos que aquí se analizan el papel de los diputados locales y federales fue totalmente irrelevante.

Podemos decir que Mario Velásquez acepta lo que afirma Melucci al decir que la lógica que asume la acción colectiva en la sociedad de información guarda más relación con lo que fueron los movimientos estudiantiles en Francia, México, Estados Unidos y Japón en la década de los sesenta que con lógicas de gran alcance y duración, con proyectos revolucionarios que cuestionen un orden político que abarca todas las esferas de la vida social, como lo fueron el movimiento obrero y las organizaciones políticas como los partidos comunistas.

También hay que mencionar que las acciones de los ecologistas y los campesinos en Hermosillo y Tepoztlán adoptaron un carácter cíclico en donde la acción colectiva no fue continua sino que experimentó periodos activos y periodos de latencia. Este carácter discontinuo, contingente, de la acción de ciudadanos y campesinos permite comprender por qué existe una dialéctica entre lo visible y lo invisible, entre lo abierto y lo clandestino, entre lo latente y lo manifiesto, entre lo privado y lo público, entre lo comunitario y lo estrictamente social, que es precisamente lo que diferencia a estos movimientos de los que tuvieron lugar antes de 1980.

Lo recurrente de las acciones que estudia Mario Velásquez y los frecuentes cambios de los adversarios (primero una empresa, después el gobierno estatal y al final el gobierno federal, con múltiples ires y venires entre estos agentes) demuestran nuevamente que se trata de articulaciones diferentes de los elementos constitutivos de la acción colectiva.

A la vez, si bien tanto en Hermosillo como en Tepoztlán las acciones resistieron a la imposición y a lo arbitrario, no por ello dejaron de ser portadoras de una herencia del pasado: su acción estuvo dirigida a hacer visible lo invisible, a desnudar lo oculto, a descifrar códigos que eran difíciles de percibir porque eran esencialmente simbólicos. En el caso de Tepoztlán el conflicto del campo de golf reencarnó la épica de Rubén Jaramillo, y por ello nos obliga a reformular incluso lo que fueron las interpretaciones de este movimiento. Las luchas verdes también tienen que ver con el lenguaje y su sentido, es decir, con la comunicación concebida como recurso, como capital en la movilización 
de los actores; además tienen que ver con la búsqueda de mecanismos de control del comportamiento en espacios privados y públicos con las posibilidades de la acción autónoma.

Éstas son algunas de las ideas que suscita la lectura de Las luchas verdes. Su aporte a la conceptuación del sentido de la acción colectiva en el México de hoy, así como a la reconstrucción de dos manifestaciones típicas de este periodo de la historia del país, dan fe del valor del análisis sociológico para comprender la realidad social en épocas complejas como las que nos ha tocado vivir. 